\title{
UV-Irradiated Photocatalytic Degradation of Nitrobenzene by Titania Binding on Quartz Tube
}

\author{
Thou-Jen Whang, Mu-Tao Hsieh, Tjaun-En Shi, and Chun-Hsiung Kuei \\ Department of Chemistry, National Cheng Kung University, No. 1 University Road, Tainan 70101, Taiwan \\ Correspondence should be addressed to Thou-Jen Whang, twhang@mail.ncku.edu.tw
}

Received 25 June 2012; Revised 24 September 2012; Accepted 26 September 2012

Academic Editor: Jiaguo Yu

Copyright (๑) 2012 Thou-Jen Whang et al. This is an open access article distributed under the Creative Commons Attribution License, which permits unrestricted use, distribution, and reproduction in any medium, provided the original work is properly cited.

\begin{abstract}
A new method for UV-irradiated degradation of nitrobenzene by titania photocatalysts was proposed, titania nanoparticles were coated on a quartz tube through the introduction of tetraethyl orthosilicate into the matrix. The dependence of nitrobenzene photodegradation on $\mathrm{pH}$, temperature, concentration, and air feeding was discussed, and the physical properties such as the activation energy, entropy, enthalpy, adsorption constant, and rate constant were acquired by conducting the reactions in a variety of experimental conditions. The optimum efficiency of the photodegradation with the nitrobenzene residue as low as $8.8 \%$ was achieved according to the experimental conditions indicated. The photodegradation pathways were also investigated through HPLC, GC/MS, ion chromatography (IC), and chemical oxygen demand (COD) analyses.
\end{abstract}

\section{Introduction}

Wastewater discharged from industrial effluents has been a serious problem of the environmental issues [1]. Due to the relatively stable chemical structures of aromatic dyes, most of the dyestuffs that the industries produced are unlikely to decompose and therefore causing severe contaminations to the drinking water and irrigation systems. Many of the dyestuffs have even been considered health hazards and thus serious concerns have been raised $[2,3]$. Nitrobenzene (NB) is one of the frequently used chemicals for aniline manufacturing, rubber making, textile, pesticide, cosmetic, and pharmaceutical purposes [4]. It is a highly toxic pollutant. Through skin contact and inhalation, it is readily absorbed into human body and is likely causing symptoms such as headache, vertigo, vomit, and weakness. For this reason, it was selected to be the model pollutant in this study. General treatments of such polluted wastewater include adsorption [5, 6], ozonation [7], or biodegradation [8]. However, those methods are somewhat inefficient or relatively expensive because they require further treatments and are very prone to cause secondary pollution.
Semiconductor photocatalysts have been considered potential candidates for treating various water pollutants [911] and are acclaimed as being one of advanced oxidation processes for eliminating the harmful contaminants. The efficient oxidation reaction of photocatalysts under UV irradiation processes provides an alternative way of managing these pollutants properly. Due to the extensive research for many years, semiconductor photocatalysts which have been frequently investigated include oxide compounds of $\mathrm{TiO}_{2}$, $\mathrm{ZnO}, \mathrm{WO}_{3}, \mathrm{SnO}_{2}, \mathrm{ZrO}_{2}$, and sulfide compounds of $\mathrm{CdS}$ and $\mathrm{ZnS}[12,13]$. Among these compounds, titania $\left(\mathrm{TiO}_{2}\right)$ has been thoroughly investigated for its photocatalytic activities [14-18]. Novel preparations of titania with high photocatalytic activities have been proposed $[19,20]$. It has drawn great attention in research and industries in recent years owing to its powerful oxidation capability, non-toxicity, biological inertness, chemical stability, and costeffectiveness [21]. Recently, selective photocatalysis of titania has been developed and gained success, it can be applied to separation process or selective elimination of specific molecules from a mixture $[22,23]$. Some research explored further the photocatalytic activities of mixed oxides [24], and some 
studied the effect of morphologies of titania $[25,26]$. In addition, titania photocatalysis has been applied to solar disinfection of water [27] and degrading chemicals that caused hormonal imbalance in wildlife and humans [28].

The initial step involves the generation of $\mathrm{e}^{-} / \mathrm{h}^{+}$pairs after irradiated with light of which the wavelength is shorter than $388 \mathrm{~nm}$ ( $413 \mathrm{~nm}$ for rutile crystalline phase), due to the wide direct band gap of $\mathrm{TiO}_{2}(3.2,3.0 \mathrm{eV}$ for anatase and rutile crystalline phase, resp.), the valence band electrons of $\mathrm{TiO}_{2}$ will be promoted up to the conduction band, leaving holes in valence band as shown in (1). The holes produced could subsequently react with $\mathrm{H}_{2} \mathrm{O}$ molecules or hydroxide ions $\left(\mathrm{OH}^{-}\right)$in aqueous solution forming powerful oxidants such as hydroxyl radicals $\left({ }^{\bullet} \mathrm{OH}\right)$ in (2). The electrons on conduction band could transform the dissolved oxygen to superoxide radicals in (3) and further to hydrogen peroxide in (4)-(7) [29]. These strong oxidants could be used to mineralize organic pollutants from wastewater as follows:

$$
\begin{gathered}
\mathrm{TiO}_{2}+h v \longrightarrow \mathrm{TiO}_{2}\left(\mathrm{e}^{-}+\mathrm{h}^{+}\right) \\
\mathrm{h}^{+}+\mathrm{H}_{2} \mathrm{O} \longrightarrow \cdot \mathrm{OH}+\mathrm{H}^{+}\left(\mathrm{h}^{+}+\mathrm{OH}^{-} \longrightarrow \cdot \mathrm{OH}\right. \\
\text { in alkaline condition }) \\
\mathrm{e}^{-}+\mathrm{O}_{2} \longrightarrow \mathrm{O}_{2}^{\bullet-} \\
\mathrm{O}_{2}^{\bullet-}+\mathrm{H}^{+} \longrightarrow \mathrm{HO}_{2}{ }^{\bullet} \\
\mathrm{HO}_{2}{ }^{-}+\mathrm{HO}_{2}{ }^{\bullet} \longrightarrow \mathrm{H}_{2} \mathrm{O}_{2}+\mathrm{O}_{2} \\
\mathrm{O}_{2}{ }^{--}+\mathrm{HO}_{2}{ }^{\bullet} \longrightarrow \mathrm{HO}_{2}^{-}+\mathrm{O}_{2} \\
\mathrm{HO}_{2}^{-}+\mathrm{H}^{+} \longrightarrow \mathrm{H}_{2} \mathrm{O}_{2} .
\end{gathered}
$$

The photocatalytical degradation of NB may undergo either through direct oxidation reduction from electrons and holes or through indirect reaction with oxidants such as hydroxyl radicals, superoxide radicals, and hydrogen peroxide, which are generated by UV irradiation onto $\mathrm{TiO}_{2}$.

The aim of this study is to investigate the optimized experimental conditions for the photodegradation of NB and to propose a new approach which can easily be applied repetitively without the necessity of separating the catalyst from solution after use. By employing HPLC, GC/MS, ion chromatography (IC), and chemical oxygen demand (COD) analyses, the authors attempted to probe into the photodegradation pathways. The structural and optical characterization of $\mathrm{TiO}_{2}$ has been done by means of Xray diffraction (XRD) and UV-vis spectroscopy (UV-vis). The photocatalytic activities of $\mathrm{TiO}_{2}$ nanoparticles were evaluated through the degradations of NB solutions initiated by irradiation with an UV lamp.

\section{Experimental}

2.1. Materials. Degussa P25 titania $\left(\mathrm{TiO}_{2}, 80 \%\right.$ in anatase phase, average particle size $30 \mathrm{~nm}$, surface area $50 \mathrm{~m}^{2} \mathrm{~g}^{-1}$ ) was acquired from Degussa Co. Nitrobenzene was purchased from Panreac Co., $m$-, $o$-, $p$-nitrophenol, tetraethyl orthosilicate, perchloric acid, HPLC grade methanol, sodium nitrate, sodium nitrite, sodium carbonate, and sodium bicarbonate were acquired from Merck Co. Ethanol was purchased from Riedel-de Haen Co. Coumarin was purchased from Alfa Aesar Co. These chemicals were used without further purification. Ultrapure water $(18 \mathrm{M} \Omega-\mathrm{cm})$ was used throughout the entire experiments.

\subsection{Preparation of Tetraethyl Orthosilicate Polymer Solution. One mole of tetraethyl orthosilicate and $2.5 \mathrm{moL}$ ethanol were mixed for $30 \mathrm{~min}$ at room temperature, hydrochloric acid solution was added to make the solution with a $\mathrm{pH}$ value of $\mathrm{pH}$. Then a mixture of $2.5 \mathrm{moL}$ ethanol and $4 \mathrm{moL}$ $\mathrm{H}_{2} \mathrm{O}$ was added into the solution above for $30 \mathrm{~min}$ to form a polymer solution which is in molar ratio of $1: 4: 5$ for tetraethyl orthosilicate, $\mathrm{H}_{2} \mathrm{O}$, and ethanol. A quartz tube $(2.2 \mathrm{~cm}$ in outer diameter and $28 \mathrm{~cm}$ in length) was first dipped into the solution composed of $\mathrm{TiO}_{2}$ and polymer $(1: 20 \mathrm{w} / \mathrm{w}$ ratio $)$ three times and was sintered in an oven at $400^{\circ} \mathrm{C}$ for $1 \mathrm{~h}$.}

2.3. NB Photodegradation Reactions. A $482 \mathrm{~mL}$ stainless steel tank was used as the container for $\mathrm{TiO}_{2}$ photocatalytic degradation of NB solutions, inside the container the water bath was circulated by a peristaltic pump at a flow rate of $73 \mathrm{~mL} \mathrm{~min}^{-1}$ and thermostated by a HAAKE DC10 immersion circulator at $30^{\circ} \mathrm{C}$. The quartz tube referred to above was put inside a glass tube, which is $5 \mathrm{~cm}$ in inner diameter and $30 \mathrm{~cm}$ in length and was used as the batch reactor. A $14 \mathrm{~W}$ Philips UV lamp with the wavelength of $254 \mathrm{~nm}$ was inserted into the quartz tube. Silicone tubing was introduced inside the reactor for feeding air into the solution. The degradation experiments were carried out by mixing each $400 \mathrm{~mL}$ of $0.407,0.813,1.220,1.626$, and $2.439 \mathrm{mM}$ NB solution with $0.2 \mathrm{~g} \mathrm{TiO}_{2}$ photocatalyst supported on the quartz tube and covered with aluminum foil, the selected air feeding was 50,100 , and $150 \mathrm{~mL} \mathrm{~min}^{-1}$ (the dissolved oxygen is $5.8,6.5$, and $7.2 \mathrm{mg} \mathrm{L}^{-1}$, resp.), the $\mathrm{pH}$ values of solutions were adjusted to $\mathrm{pH} 4,7$, and 11 using $0.1 \mathrm{~N}$ perchloric acid or $0.1 \mathrm{~N} \mathrm{NaOH}$ solution. The solutions were sampled at 0 , $15,30,45,60,90,120,150$, and $180 \mathrm{~min}$ reaction time for HPLC, IC, and GC/MS analyses. The absorption maximum of the UV-vis absorbance spectroscopy appeared at $270 \mathrm{~nm}$ $\left(\lambda_{\max }\right)$ for NB solutions and was selected to be the analytical wavelength for NB measurements. For the identifications of intermediates, the photodegradation was manipulated in a slurry system with $1.0 \mathrm{~g}$ catalyst and $1.626 \mathrm{mM} \mathrm{NB}$ at $\mathrm{pH} 7$ and $30^{\circ} \mathrm{C}$ with the air feeding of $150 \mathrm{~mL} \mathrm{~min}^{-1}$ for $10 \mathrm{~h}$.

\subsection{Characterization of $\mathrm{TiO}_{2}$ Nanoparticles and Quantitative Analyses of Reaction Intermediates. A Shimadzu XD-D1 X- ray diffractometer was used to observe the XRD patterns of nanoparticles, and the $2 \theta$ range of $20^{\circ}$ to $70^{\circ}$ was scanned continuously with a step of $0.02^{\circ}$ and at a speed of 1 degree $\mathrm{min}^{-1}$. A Hitachi U-2000 UV-vis spectrophotometer was used to evaluate the degradation of NB solutions, the absorption maximum $\left(\lambda_{\max }\right)$ of the UV-vis absorbance spectroscopy of NB solutions was selected at $270 \mathrm{~nm}$ based on analytical sensitivity. A Hitachi L-7000 high-performance}


liquid chromatography (HPLC; Hitachi L-7100 pump) using a C18 column (Waters $5 \mu \mathrm{m}, 250 \mathrm{~mm}$ long) connected with a Hitachi L-7420 UV detector was used for the qualitative and quantitative determinations of the initial compound and reaction intermediates. A Dionex DX-120 ion chromatography (IC) system using IonPac AS9-HC analytical column $(4 \times 250 \mathrm{~mm}, 1700-1800 \mathrm{psi})$ and IonPac AG9-HC guard column $(4 \times 50 \mathrm{~mm})$ with $9 \mathrm{mM} \mathrm{Na} \mathrm{CO}_{3}$ as the mobile phase was used for the qualitative and quantitative determinations of anions produced during the reaction. A Finnigan Trace MS connected with Trace GC 2000 GC/MS in electron impact (EI) mode were used to separate and analyze the intermediates of reaction. Samples were injected splitless into the gas chromatography equipped with a Rtx$5 \mathrm{~ms}$ column $(30 \mathrm{~m} \times 0.25 \mathrm{~mm}, 0.25 \mu \mathrm{m}$ film thickness). The oven was programmed isotherm at $35^{\circ} \mathrm{C}$ for $2 \mathrm{~min}$, then heating from $35^{\circ} \mathrm{C}$ to $250^{\circ} \mathrm{C}$ at the speed of $10^{\circ} \mathrm{C} \mathrm{min}^{-1}$, and keep isotherm at $250^{\circ} \mathrm{C}$ for $1 \mathrm{~min}$. An AQUALYTIC AL31 chemical oxygen demand reactor was used to detect the amount of organic compound residue in solution.

2.5. Measurements of Hydroxyl Radicals Generated from Titania under UV Irradiation. The measurement of hydroxyl radicals was proposed using coumarin or terephthalic acid as probe molecules $[30,31]$. Coumarin was selected as the probe molecule in this work. Each $0.1 \mathrm{~g}$ titania powder was dispersed in $20 \mathrm{~mL} 1.0 \mathrm{mM}$ coumarin aqueous solution until it reached adsorption-desorption equilibrium before light irradiation. In a dish with $7.0 \mathrm{~cm}$ in diameter, the solution was located $10 \mathrm{~cm}$ below the light source and was irradiated using an UV lamp with the peak intensity of $366 \mathrm{~nm}$. After UV illumination the solution was centrifuged and the PL spectrum of hydroxylated coumarin (7-hydroxycoumarin) was measured by a Hitachi F-4500 fluorescence spectrophotometer with the excitation wavelength of $332 \mathrm{~nm}$, scanning speed $240 \mathrm{~nm} / \mathrm{min}$, PMT voltage $700 \mathrm{~V}$, and slit width $2.5 \mathrm{~nm}$. To investigate the effect of $\mathrm{pH}$ value on the production of hydroxyl radicals, the coumarin solution was adjusted to $\mathrm{pH} 4,7$, and 11 using $0.1 \mathrm{~N}$ perchloric acid or 0.1 $\mathrm{N} \mathrm{NaOH}$ solution.

\section{Results and Discussion}

3.1. Background Experiments. To explore the background interferences, volatility of solvent, adsorption, and blank experiments were carried out to confirm the role of titania in the photocatalysis reactions. The results of volatility experiments showed no significant decrease of NB concentration was observed after $3 \mathrm{~h}$. With respect to the adsorption of NB by the catalysts, the adsorption tests showed that saturated adsorption of NB was reached after about $150 \mathrm{~min}$ of adsorption. The results of blank experiments (direct photocatalysis of NB solution without the catalysts) showed more than $71.1 \% \mathrm{NB}$ remained after $3 \mathrm{~h}$ irradiation under a variety of conditions. Therefore, the concentrations of NB were examined after $3 \mathrm{~h}$ of adsorption for all the degradation experiments.

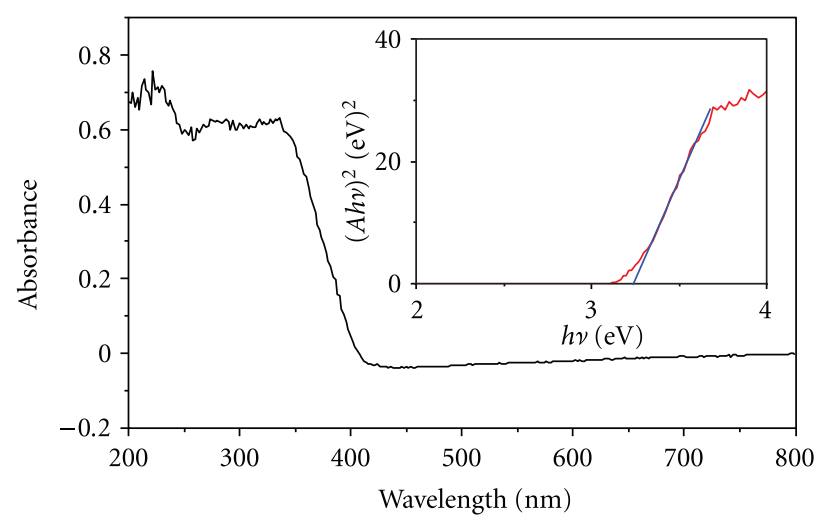

FIgURE 1: The UV-vis absorbance spectrum of $\mathrm{TiO}_{2}$ photocatalyst. Inset shows the plot of $(A h v)^{2}$ versus $h v$ for $\mathrm{TiO}_{2}$, the straight line represents the extrapolation of the abscissa from the linear fit of the curve, through which the band gap was estimated at about $3.20 \mathrm{eV}$.

3.2. Characterization of $\mathrm{TiO}_{2}$ Photocatalysts. From the UVvis spectrum in Figure 1, very little light could be absorbed in the spectrum with wavelength greater than $420 \mathrm{~nm}$ by semiconductor $\mathrm{TiO}_{2}$. The energy gap of $\mathrm{TiO}_{2}$ nanoparticles can be obtained from the data treatment of optical absorbance by plotting $(A h v)^{2}$ versus $h v$ according to the following relationship $[32,33]$ :

$$
A=\frac{\left[k\left(h v-E_{g}\right)^{n / 2}\right]}{h v},
$$

where $A$ is the absorbance, $k$ is a constant, $h$ is the Planck's constant, $v$ is the frequency of light, $n=1$ for direct and $n=4$ for indirect electron transfer, and $E_{g}$ is the band gap of the object concerned. From the inset of Figure 1, P25 $\mathrm{TiO}_{2}$ was estimated having the energy gap of $3.2 \mathrm{eV}$, which is in accordance with other research [34]. From the XRD patterns of $\mathrm{TiO}_{2}$ photocatalysts (not shown), the characteristic signals of anatase crystalline phase $\mathrm{TiO}_{2}$ were found at $2 \theta=25.4^{\circ}(1$ $01), 37.9^{\circ}\left(\begin{array}{lll}0 & 0 & 4\end{array}\right), 48.2^{\circ}\left(\begin{array}{lll}2 & 0 & 0\end{array}\right), 55.1^{\circ}$ (2 111$), 62.8^{\circ}$ (2 0 4 ), and the signals for rutile crystalline phase at $27.5^{\circ}$ (1 1 $0), 36.2^{\circ}\left(\begin{array}{lll}1 & 0 & 1\end{array}\right), 54.4^{\circ}\left(\begin{array}{lll}2 & 1 & 1\end{array}\right)$. Using the Scherrer equation with a shape factor of $0.89, \lambda=0.1541 \mathrm{~nm}$ for the wavelength of the $\mathrm{Cu} \mathrm{K} \alpha_{1} \mathrm{X}$-ray source, and $B$ the full peak width at half-maximum, the particle size ( $d$; in $\mathrm{nm}$ ) of nanoparticles can be estimated [35]. Applying XRD data of P25 $\mathrm{TiO}_{2}$ nanoparticles to the equation above, the particle size was evaluated at $18.1 \mathrm{~nm}$. Furthermore, the ratio of anatase phase in those nanoparticles can be evaluated according to the following equation [36]:

$$
A(\%)=\frac{100}{\left(1+1.265 I_{R} / I_{A}\right)},
$$

where $I_{R}$ is the intensity of the peak at $2 \theta=27.5^{\circ}$ and $I_{A}$ is the intensity of the peak at $2 \theta=25.3^{\circ}$ (those are the most prominent signals of rutile and anatase form, resp.). By using this equation, the anatase phase ratio in $\mathrm{P} 25 \mathrm{TiO}_{2}$ is estimated at $84 \%$. 


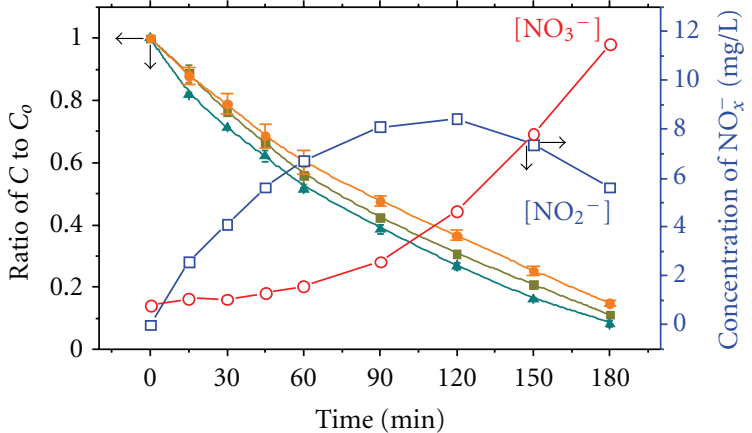

FIGURE 2: UV photocatalytic degradation of nitrobenzene at $\mathrm{pH} 4$ (blue line with square symbols), 7 (green line with triangle symbols), and 11 (orange line with round symbols) with $0.2 \mathrm{~g} \mathrm{TiO}_{2}$ at $30^{\circ} \mathrm{C}$ and the air feeding of $150 \mathrm{~mL} \mathrm{~min}^{-1}$ for $3 \mathrm{~h}$. Concentrations of reaction intermediates nitrate (red line with empty circles) and nitrite ions (blue line with empty squares) at $\mathrm{pH} 7$ are corresponded to the right ordinate as time changes.

\subsection{Effects of $p H$ on Photocatalytic Degradation of Nitroben-} zene. The effects of $\mathrm{pH}$ on the photocatalytic degradation of nitrobenzene are shown in Figure 2. According to the degradation processes carried out in $\mathrm{pH} 4,7$, and 11, the most efficient degradation is in the case of $\mathrm{pH} 7$ and the least one is in the case of $\mathrm{pH} 11$. Because the surface of $\mathrm{TiO}_{2}$ catalysts in aqueous solution is in the form of Ti-OH $[37,38]$, and the $\mathrm{pH}$ of zero point charge $\left(\mathrm{pH}_{\mathrm{zpc}}\right)$ is about 6-6.4 for anatase phase and 5.8 for rutile phase [39]. In circumstance of $\mathrm{pH}$ value less than $\mathrm{pH}_{\mathrm{zpc}}$, the major species on the surface of catalysts in the form of Ti- $\mathrm{OH}_{2}{ }^{+}$is likely to occur whereas with a $\mathrm{pH}$ greater than $\mathrm{pH}_{\mathrm{zpc}}$ the negative form of $\mathrm{Ti}^{-} \mathrm{O}^{-}$is prone to happen. To produce strong performance of the photocatalytic reaction, it is important to have fair interaction between the substance to be degraded and the catalysts [40]. Therefore, the $\mathrm{pH}$ value of the solution plays a significant role in the interactions between the surface of $\mathrm{TiO}_{2}$ and the instinctive electron property of the degrading substance. In the case of NB molecule, it is very likely to be in the form of positive charge because of the low $p K_{a}$ for NB [41].

Another aspect of the $\mathrm{pH}$ effects that comes into play is the formation of ${ }^{\bullet} \mathrm{OH}$ radicals being more feasible in low $\mathrm{pH}$ condition [30], which is shown in Figure 3 that hydroxyl radicals generated at $\mathrm{pH} 4$ has more amount than those in $\mathrm{pH} 7$ and 11. According to the results shown in Figure 2, combining the effects cited above indicate the interaction between the substance and surface has more influence on the catalytical effect than the generation of ${ }^{\bullet} \mathrm{OH}$ radicals. The additional data included in Figure 2 are the concentrations of intermediates $\mathrm{NO}_{3}{ }^{-}, \mathrm{NO}_{2}{ }^{-}$which were generated during the degradation processes. The nitrite ions detected were assumed to be generated through the cleavage of nitro group on NB molecules. The nitrate ions were further produced through the oxidation of nitrite ions by the oxidants which were initiated by the UV irradiation of the catalysts and generated by a variety of reactions. These can be demonstrated from the observed trend in Figure 2 how the concentration of nitrites reached the peak at $120 \mathrm{~min}$ and

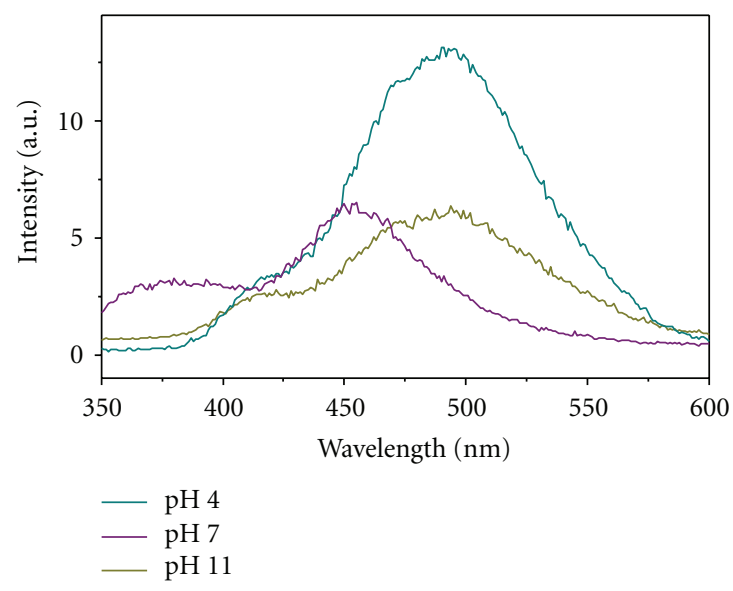

FIGURE 3: PL spectra of hydroxylated coumarin (7-hydroxycoumarin) solutions adjusted at $\mathrm{pH} 4,7$, and 11 . Each $1.0 \mathrm{mM}$ coumarin aqueous solution was mixed with $0.1 \mathrm{~g} \mathrm{TiO}_{2}$ and irradiated thereafter using an UV lamp with the peak intensity of $366 \mathrm{~nm}$ for $15 \mathrm{~min}$.

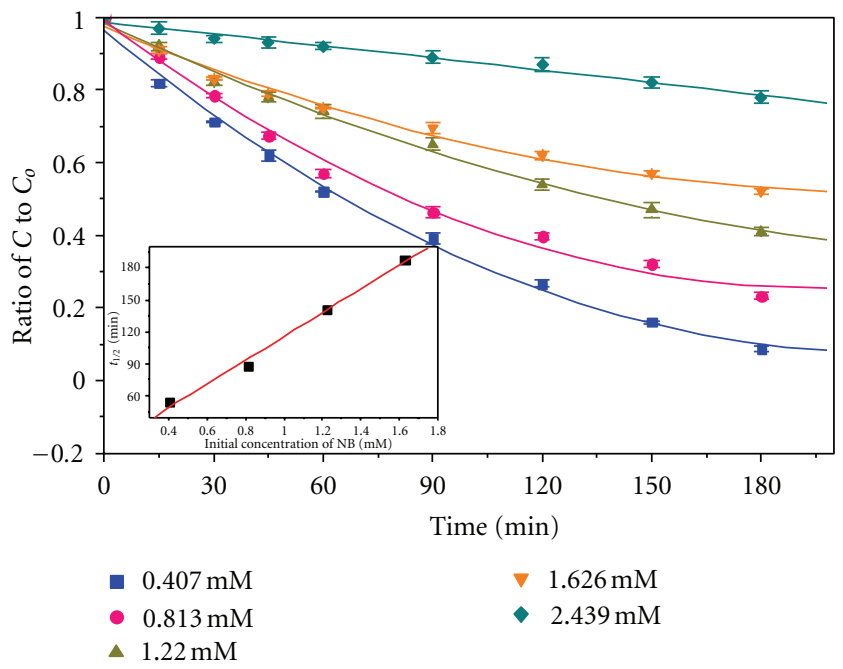

FIgURE 4: The initial concentration dependence of reaction rates for the photodegradation of nitrobenzene by $\mathrm{TiO}_{2}$ as time changes. The processes were operated with $0.2 \mathrm{~g} \mathrm{TiO}_{2}$ and various concentrations of nitrobenzene at $\mathrm{pH} 7$ and $30^{\circ} \mathrm{C}$ with the air feeding of $150 \mathrm{~mL} \mathrm{~min}{ }^{-1}$ for $3 \mathrm{~h}$. Inset shows the effect of the initial concentrations on the half-life of NB.

since then nitrates increased at the expense of nitrites. This observation will be discussed along with the investigation of mechanisms in later section.

3.4. Physical Properties of the Photodegradation Reaction. Figure 4 exhibits the initial concentration dependence of reaction rates for $\mathrm{NB}$ photodegradation. To examine whether this reaction follows the Langmuir-Hinshelwood dynamic model, a graph of $t_{1 / 2}$ versus $C_{o}$ was plotted according to the following equation [42]:

$$
t_{1 / 2}=\left(\frac{0.693}{k_{\mathrm{LH}} K_{\mathrm{ads}}}\right)+\left(\frac{0.5}{k_{\mathrm{LH}}}\right) C_{o},
$$




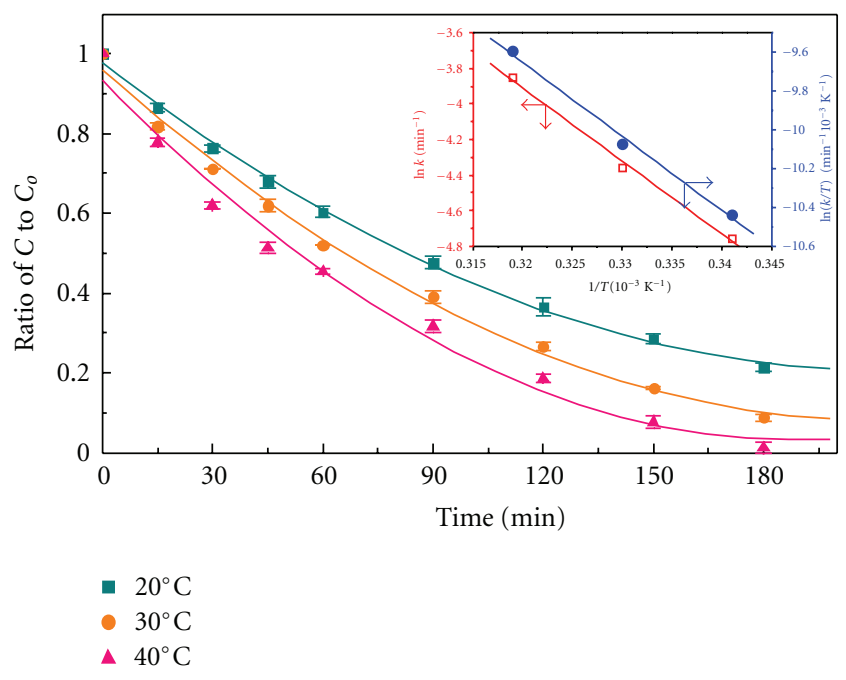

Figure 5: The temperature dependence of nitrobenzene photodegraded by $\mathrm{TiO}_{2}$ as time changes. The processes were operated with $0.2 \mathrm{~g} \mathrm{TiO}_{2}$ and $0.407 \mathrm{mM}$ nitrobenzene at $\mathrm{pH} 7$ and $20^{\circ} \mathrm{C}, 30^{\circ} \mathrm{C}$, $40^{\circ} \mathrm{C}$ with the air feeding of $150 \mathrm{~mL} \mathrm{~min}^{-1}$ for $3 \mathrm{~h}$. Inset shows the linear fits of the data for $\ln k$ and $\ln (k / T)$ versus the reciprocal of temperature.

where $t_{1 / 2}$ is the half-life of the reactant, $k_{\mathrm{LH}}$ is the rate constant of photocatalytic reaction, $K_{\mathrm{ads}}$ is the adsorption constant of reactant, and $C_{o}$ is the initial concentration of the reactant. While the reactions were conducted under the condition of $0.2 \mathrm{~g} \mathrm{P} 25 \mathrm{TiO}_{2}$, at $\mathrm{pH} 7$ and $30^{\circ} \mathrm{C}$ with the air feeding of $150 \mathrm{~mL} \mathrm{~min}^{-1}$, by deriving from the slope and intercept of the linear fitted line, the following constants were acquired: $k_{\mathrm{LH}}$ is $4.48 \times 10^{-3} \mathrm{mM} \mathrm{min}^{-1}$, and $K_{\mathrm{ads}}$ is $36.02 \mathrm{mM}^{-1}$ for NB , as shown in the inset of Figure 4.

The temperature dependence of reaction rates is shown in Figure 5, the reactions were carried out under the conditions of $0.2 \mathrm{~g} \mathrm{TiO}_{2}$ at $\mathrm{pH} 7$ with the air feeding of $150 \mathrm{~mL} \mathrm{~min}^{-1}$ for $3 \mathrm{~h}$ at temperatures of $20^{\circ} \mathrm{C}, 30^{\circ} \mathrm{C}, 40^{\circ} \mathrm{C}$, respectively. According to the Arrhenius equation and the transition state theory [43], one can obtain the values of activation energy, entropy, and enthalpy of the reaction through the applications of these equations. From the left ordinate of the inset in Figure 5, the linear fit of the data is $\ln k=-4143.8(1 / T)+9.3549$ with the activation energy of $34.45 \mathrm{~kJ} \mathrm{moL}^{-1}$. The enthalpy and entropy of reaction can be evaluated from the linear fit of the data with the right ordinate $\ln (k / T)=-38.436+2.6511$ : with $\Delta H=$ $0.31 \mathrm{~kJ} \mathrm{moL}^{-1}$ and $\Delta S=-0.041 \mathrm{~J} \mathrm{moL}^{-1} \mathrm{~K}^{-1}$.

\subsection{The Air Feeding Dependence of the Photodegradation} Reaction. The air feeding dependence of NB photodegradation by $\mathrm{TiO}_{2}$ is shown in Figure 6. The processes were conducted with $0.2 \mathrm{~g} \mathrm{TiO}_{2}$ and $0.407 \mathrm{mM} \mathrm{NB}$ at $\mathrm{pH} 7$ and $30^{\circ} \mathrm{C}$ for $3 \mathrm{~h}$. The dissolved oxygen brought into the solution by air feeding could be used as the scavenger of the electrons on $\mathrm{TiO}_{2}$ which were excited by UV irradiation. This can prevent the recombination of the photogenerated $\mathrm{e}^{-} / \mathrm{h}^{+}$pairs since with such recombination, the efficiency of catalysts decreases dramatically. Furthermore, with large quantity

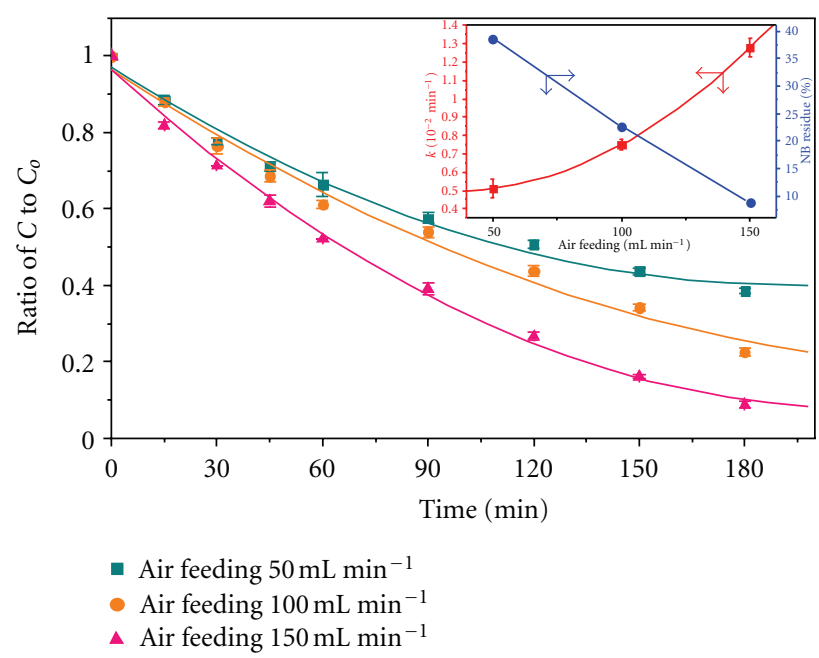

FIGURE 6: The air feeding dependence of nitrobenzene photodegraded by $\mathrm{TiO}_{2}$ as time changes. The processes were operated with $0.2 \mathrm{~g} \mathrm{TiO}_{2}$ and $0.407 \mathrm{mM}$ nitrobenzene at $\mathrm{pH} 7$ and $30^{\circ} \mathrm{C}$ for $3 \mathrm{~h}$. Inset shows the relationships between the air feeding and rate constant, NB residue, respectively.

of dissolved oxygen in solution, more oxygen radicals will be produced and as they are adsorbed on the surface of $\mathrm{TiO}_{2}$, these radicals will react further with $\mathrm{H}_{2} \mathrm{O}$ molecules to generate $\cdot \mathrm{OH}$, which enhances the rate constants and therefore the efficiency of catalysts as shown in the inset of Figure 6. The results from the photodegradation in Figure 6 reveal that the larger amount of air feeding supplies the stronger performance it delivers, which is correspondent with the discussion above.

3.6. Investigation of the Mechanisms for NB Photodegradation Reaction. It has been proposed that the photodegradation pathway of $\mathrm{NB}$ is related to partial oxidation of $\mathrm{NB}$ to hydroxyl derivatives [44], such as $m-, o-, p$-nitrophenol. To investigate the mechanisms of this photodegradation reaction, the solutions were prepared as indicated in experimental section and were sampled at every half hour interval and up to $10 \mathrm{~h}$ of the reacting time span for HPLC separation and identification. According to the characteristic retention times of HPLC authentic standards for the analytes, which is $6.4 \mathrm{~min}$ for $m$-nitrophenol, $8.7 \mathrm{~min}$ for $o$-nitrophenol, $5.7 \mathrm{~min}$ for $p$-nitrophenol, and $9.2 \mathrm{~min}$ for $\mathrm{NB}$, the reaction intermediates can be identified with these data accordingly.

The concentration changes of the intermediates of NB photodegradation with corresponding time are shown in Figure 7 , the total concentration of the intermediates is less than $7 \mu \mathrm{M}$, and it is conspicuous that $m$-nitrophenol was produced at the highest rate and p-nitrophenol the second highest for the initial $2 \mathrm{~h}$ of reaction and since then both decreased briskly while $o$-nitrophenol remained an approximate concentration level during this period. GC/MS analyses were also used to confirm the reaction intermediates. The $\mathrm{pH}$ decrease from the start of reaction of $\mathrm{pH} 5.84$ to $\mathrm{pH} 3.82$ after $3 \mathrm{~h}$ of reaction was observed as 


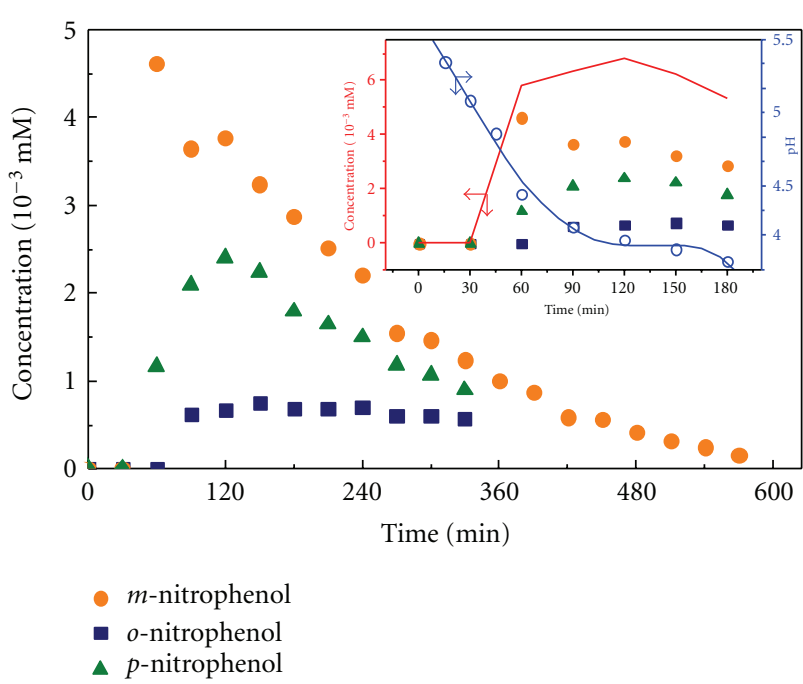

Figure 7: The concentration changes of intermediates $m-, o^{-}, p$ nitrophenol as time changes. The photodegradation processes were operated with $1.626 \mathrm{mM}$ nitrobenzene and $1.0 \mathrm{~g} \mathrm{TiO}_{2}$ at $\mathrm{pH} 7$ and $30^{\circ} \mathrm{C}$ with the air feeding of $150 \mathrm{~mL} \mathrm{~min}^{-1}$ for $10 \mathrm{~h}$. Inset shows the relationship between $\mathrm{pH}$ changes and the total concentration of intermediates (in red line) for the initial $3 \mathrm{~h}$ of reaction.

shown in the inset of Figure 7. The $\mathrm{pH}$ value of $m-, o^{-}, p-$ nitrophenol aqueous solution of the same concentration was measured as 6.16, 5.74, and 5.98, respectively. Combining these results with the generation of nitrites and nitrates from Figure 2, it can be assumed that the NB photodegradation reaction involves hydroxyl group grafting on NB molecules and undergoing the nitro group cleavage from the molecules.

After the photodegradation reaction, $8.8 \% \mathrm{NB}$ residue was observed from a system of $0.2 \mathrm{~g} \mathrm{TiO}_{2}$ and $0.407 \mathrm{mM} \mathrm{NB}$ at $\mathrm{pH} 7$ and $30^{\circ} \mathrm{C}$ with the air feeding of $150 \mathrm{~mL} \mathrm{~min}^{-1}$ for $4 \mathrm{~h}$ of photocatalysis whereas $4 \%$ residue from COD analysis was achieved with the same condition, it suggests that the mineralization of $\mathrm{NB}$ to $\mathrm{CO}_{2}$ and $\mathrm{H}_{2} \mathrm{O}$ may occur in parallel with the pathway cited above.

\section{Conclusions}

A new method of photocatalytic degradation of NB was proposed by coating the titania nanoparticles on a quartz tube through the introduction of tetraethyl orthosilicate into the matrix. Some parameters were discussed herein, such as the dependence of $\mathrm{pH}$, temperature, air feeding on the photocatalysis, and some physical properties such as the activation energy, entropy, enthalpy, adsorption constant, and rate constant were also acquired. The photodegradation pathway was further investigated through HPLC, GC/MS, IC, and COD analyses.

The optimum efficiency of the photodegradation with $\mathrm{NB}$ residue as low as $8.8 \%$ was achieved with the experimental conditions mentioned. Although it is not the most efficient result compared to those from other studies, one of the advantages of practicing the NB photodegradation by adopting this approach is that the necessity of separating the catalyst from solution after use is not required and therefore making it easy to be applied repetitively. With these considerations, treating the wastewater from the industries by UV photocatalytic mineralization of organic pollutants using $\mathrm{TiO}_{2}$ photocatalyst coated on quartz tube with tetraethyl orthosilicate as the binder is one of the convenient and potential candidates for this issue.

\section{Acknowledgments}

This work was supported by National Science Council of Taiwan and National Cheng Kung University.

\section{References}

[1] E. Bizani, K. Fytianos, I. Poulios, and V. Tsiridis, "Photocatalytic decolorization and degradation of dye solutions and wastewaters in the presence of titanium dioxide," Journal of Hazardous Materials, vol. 136, no. 1, pp. 85-94, 2006.

[2] T. Robinson, G. McMullan, R. Marchant, and P. Nigam, "Remediation of dyes in textile effluent: a critical review on current treatment technologies with a proposed alternative," Bioresource Technology, vol. 77, no. 3, pp. 247-255, 2001.

[3] L. B. Reutergådh and M. Iangphasuk, "Photocatalytic decolourization of reactive azo dye: a comparison between $\mathrm{TiO}_{2}$ and CdS photocatalysis," Chemosphere, vol. 35, no. 3, pp. 585-596, 1997.

[4] P. Piccinini, C. Minero, M. Vincenti, and E. Pelizzetti, "Photocatalytic mineralization of nitrogen-containing benzene derivatives," Catalysis Today, vol. 39, no. 3, pp. 187-195, 1997.

[5] J. Pan and B. Guan, "Adsorption of nitrobenzene from aqueous solution on activated sludge modified by cetyltrimethylammonium bromide," Journal of Hazardous Materials, vol. 183, no. 1-3, pp. 341-346, 2010.

[6] A. El Sikaily, A. Khaled, A. El Nemr, and O. Abdelwahab, "Removal of Methylene Blue from aqueous solution by marine green alga Ulva lactuca," Chemistry and Ecology, vol. 22, no. 2, pp. 149-157, 2006.

[7] S. Contreras, M. Rodríguez, E. Chamarro, and S. Esplugas, "UV- and UV/Fe(III)-enhanced ozonation of nitrobenzene in aqueous solution," Journal of Photochemistry and Photobiology A, vol. 142, no. 1, pp. 79-83, 2001.

[8] L. S. Bell, J. F. Devlin, R. W. Gillham, and P. J. Binning, "A sequential zero valent iron and aerobic biodegradation treatment system for nitrobenzene," Journal of Contaminant Hydrology, vol. 66, no. 3-4, pp. 201-217, 2003.

[9] L. B. Khalil, W. E. Mourad, and M. W. Rophael, "Photocatalytic reduction of environmental pollutant $\mathrm{Cr}(\mathrm{VI})$ over some semiconductors under UV/visible light illumination," Applied Catalysis B, vol. 17, no. 3, pp. 267-273, 1998.

[10] J. Nishio, M. Tokumura, H. T. Znad, and Y. Kawase, "Photocatalytic decolorization of azo-dye with zinc oxide powder in an external UV light irradiation slurry photoreactor," Journal of Hazardous Materials, vol. 138, no. 1, pp. 106-115, 2006.

[11] J. Marugán, M. J. López-Muñoz, R. Van Grieken, and J. Aguado, "Photocatalytic decolorization and mineralization of dyes with nanocrystalline $\mathrm{TiO}_{2} / \mathrm{SiO}_{2}$ materials," Industrial and Engineering Chemistry Research, vol. 46, no. 23, pp. 7605-7610, 2007. 
[12] J. M. Herrmann, "Heterogeneous photocatalysis: fundamentals and applications to the removal of various types of aqueous pollutants," Catalysis Today, vol. 53, no. 1, pp. 115-129, 1999.

[13] S. Sohrabnezhad, "Study of catalytic reduction and photodegradation of methylene blue by heterogeneous catalyst," Spectrochimica Acta, vol. 81, no. 1, pp. 228-235, 2011.

[14] D. S. Bhatkhande, V. G. Pangarkar, and A. A. C. M. Beenackers, "Photocatalytic degradation of nitrobenzene using titanium dioxide and concentrated solar radiation: chemical effects and scaleup," Water Research, vol. 37, no. 6, pp. 1223-1230, 2003.

[15] R. J. Tayade, R. G. Kulkarni, and R. V. Jasra, "Photocatalytic degradation of aqueous nitrobenzene by nanocrystalline $\mathrm{TiO}_{2}$," Industrial and Engineering Chemistry Research, vol. 45, no. 3, pp. 922-927, 2006.

[16] R. J. Tayade and D. L. Key, "Synthesis and characterization of titanium dioxide nanotubes for photocatalytic degradation of aqueous nitrobenzene in the presence of sunlight," Materials Science Forum, vol. 657, pp. 62-74, 2010.

[17] T. J. Whang, H. Y. Huang, M. T. Hsieh, and J. J. Chen, "Laser-induced silver nanoparticles on titanium oxide for photocatalytic degradation of methylene blue," International Journal of Molecular Sciences, vol. 10, no. 11, pp. 4707-4718, 2009.

[18] D. I. Petkowicz, R. Brambilla, C. Radtke et al., "Photodegradation of methylene blue by in situ generated titania supported on a NaA zeolite," Applied Catalysis A, vol. 357, no. 2, pp. 125134, 2009.

[19] J. G. Yu, H. G. Yu, B. Cheng, X. J. Zhao, J. C. Yu, and W. K. Ho, "The effect of calcination temperature on the surface microstructure and photocatalytic activity of $\mathrm{TiO}_{2}$ thin films prepared by liquid phase deposition," Journal of Physical Chemistry B, vol. 107, no. 50, pp. 13871-13879, 2003.

[20] J. Yu, J. Xiong, B. Cheng, and S. Liu, "Fabrication and characterization of $\mathrm{Ag}-\mathrm{TiO}_{2}$ multiphase nanocomposite thin films with enhanced photocatalytic activity," Applied Catalysis $B$, vol. 60, no. 3-4, pp. 211-221, 2005.

[21] J. G. Yu, M. Jaroniec, and G. X. Lu, " $\mathrm{TiO}_{2}$ photocatalytic materials," International Journal of Photoenergy, vol. 2012, Article ID 206183, 5 pages, 2012.

[22] S. Liu, J. Yu, and M. Jaroniec, "Tunable photocatalytic selectivity of hollow $\mathrm{TiO}_{2}$ microspheres composed of anatase polyhedra with exposed 001 facets," Journal of the American Chemical Society, vol. 132, no. 34, pp. 11914-11916, 2010.

[23] Q. Xiang, J. Yu, and M. Jaroniec, "Tunable photocatalytic selectivity of $\mathrm{TiO}_{2}$ films consisted of flower-like microspheres with exposed 001 facets," Chemical Communications, vol. 47, no. 15 , pp. 4532-4534, 2011.

[24] H. Znad, M. H. Ang, and M. O. Tade, "Ta/TiO ${ }_{2}$-and Nb/TiO ${ }_{2}-$ mixed oxides as efficient solar photocatalysts: preparation, characterization, and photocatalytic activity," International Journal of Photoenergy, vol. 2012, Article ID 548158, 9 pages, 2012.

[25] J. G. Yu, Y. R. Su, and B. Cheng, “Template-free fabrication and enhanced photocatalytic activity of hierarchical macro/mesoporous titania," Advanced Functional Materials, vol. 17, no. 12, pp. 1984-1990, 2007.

[26] J. S. Wang, Q. Cai, H. G. Li, Y. T. Cui, and H. Wang, "A review on $\mathrm{TiO}_{2}$ nanotube film photocatalysts prepared by liquidphase deposition," International Journal of Photoenergy, vol. 2012, Article ID 702940, 11 pages, 2012.

[27] J. A. Byrne, P. A. Fernandez-Ibañez, P. S. M. Dunlop, D. M. A. Alrousan, and J. W. J. Hamilton, "Photocatalytic enhancement for solar disinfection of water: a review," International Journal of Photoenergy, vol. 2011, Article ID 798051, 2011.

[28] J. C. Sin, S. M. Lam, A. R. Mohamed, and K. T. Lee, "Degrading endocrine disrupting chemicals from wastewater by $\mathrm{TiO}_{2}$ photocatalysis: a review," International Journal of Photoenergy, vol. 2012, Article ID 185159, 23 pages, 2012.

[29] K. I. Okamoto, Y. Yamamoto, H. Tanaka, M. Tanaka, and A. Itaya, "Heterogeneous photocatalytic decomposition of phenol over $\mathrm{TiO}_{2}$ powder," Bulletin of the Chemical Society of Japan, vol. 58, no. 7, pp. 2015-2022, 1985.

[30] Q. Xiang, J. Yu, and P. K. Wong, "Quantitative characterization of hydroxyl radicals produced by various photocatalysts," Journal of Colloid and Interface Science, vol. 357, no. 1, pp. 163$167,2011$.

[31] J. Yu, W. Wang, B. Cheng, and B. L. Su, "Enhancement of photocatalytic activity of Mesporous $\mathrm{TiO}_{2}$ powders by hydrothermal surface fluorination treatment," Journal of Physical Chemistry C, vol. 113, no. 16, pp. 6743-6750, 2009.

[32] Z. Zainal, N. Saravanan, and H. L. Mien, "Electrodeposition of nickel selenide thin films in the presence of triethanolamine as a complexing agent," Journal of Materials Science, vol. 16, no. 2, pp. 111-117, 2005.

[33] T. J. Whang, M. T. Hsieh, J. M. Tsai, and S. J. Lee, "Lactic acid aided electrochemical deposition of c-axis preferred orientation of zinc oxide thin films: structural and morphological features," Applied Surface Science, vol. 257, no. 22, pp. 95399545, 2011.

[34] S. George, S. Pokhrel, Z. Ji et al., "Role of Fe doping in tuning the band gap of $\mathrm{TiO}_{2}$ for the photo-oxidation-induced cytotoxicity paradigm," Journal of the American Chemical Society, vol. 133, no. 29, pp. 11270-11278, 2011.

[35] I. M. Arabatzis, T. Stergiopoulos, M. C. Bernard, D. Labou, S. G. Neophytides, and P. Falaras, "Silver-modified titanium dioxide thin films for efficient photodegradation of methyl orange," Applied Catalysis B, vol. 42, no. 2, pp. 187-201, 2003.

[36] R. A. Spurr, "Quantitative analysis of anatase-rutile mixtures with an X-ray diffractometer," Analytical Chemistry, vol. 29, no. 5, pp. 760-762, 1957.

[37] D. S. Bhatkhande, S. P. Kamble, S. B. Sawant, and V. G. Pangarkar, "Photocatalytic and photochemical degradation of nitrobenzene using artificial ultraviolet light," Chemical Engineering Journal, vol. 102, no. 3, pp. 283-290, 2004.

[38] J. Yao and C. Wang, "Decolorization of methylene blue with $\mathrm{TiO}_{2}$ sol via UV irradiation photocatalytic degradation," International Journal of Photoenergy, vol. 2010, Article ID 643182, 2010.

[39] E. Pelizzetti and C. Minero, "Mechanism of the photo-oxidative degradation of organic pollutants over $\mathrm{TiO}_{2}$ particles," Electrochimica Acta, vol. 38, no. 1, pp. 47-55, 1993.

[40] B. Cheng, Y. Le, W. Cai, and J. Yu, "Synthesis of hierarchical $\mathrm{Ni}(\mathrm{OH})_{2}$ and $\mathrm{NiO}$ nanosheets and their adsorption kinetics and isotherms to Congo red in water," Journal of Hazardous Materials, vol. 185, no. 2-3, pp. 889-897, 2011.

[41] D. R. Lide, CRC Handbook of Chemistry and Physics, CRC Press, Boca Raton, Fla, USA, 2009.

[42] M. Bekbolet, A. S. Suphandag, and C. S. Uyguner, "An investigation of the photocatalytic efficiencies of $\mathrm{TiO}_{2}$ powders on the decolourisation of humic acids," Journal of Photochemistry and Photobiology A, vol. 148, no. 1-3, pp. 121-128, 2002.

[43] N. San, A. Hatipoğlu, G. Koçtürk, and Z. Çınar, "Photocatalytic degradation of 4-nitrophenol in aqueous $\mathrm{TiO}_{2}$ suspensions: theoretical prediction of the intermediates," Journal of Photochemistry and Photobiology A, vol. 146, no. 3, pp. 189197, 2002. 
[44] G. Palmisano, V. Loddo, V. Augugliaro, L. Palmisano, and S. Yurdakal, "Photocatalytic oxidation of nitrobenzene and phenylamine: pathways and kinetics," AIChE Journal, vol. 53, no. 4, pp. 961-968, 2007. 


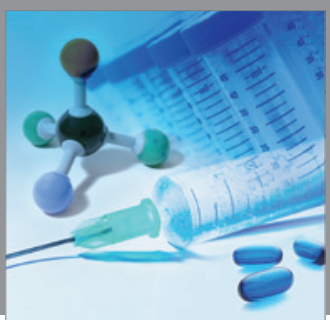

International Journal of

Medicinal Chemistry

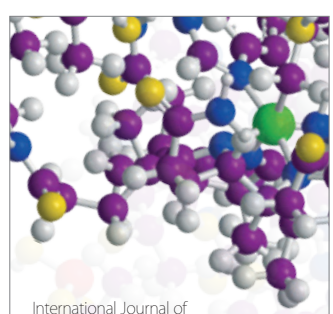

Carbohydrate Chemistry

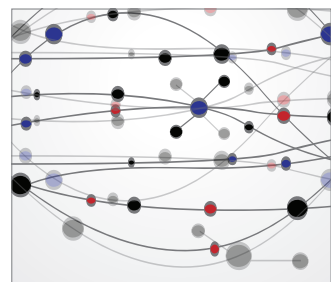

The Scientific World Journal
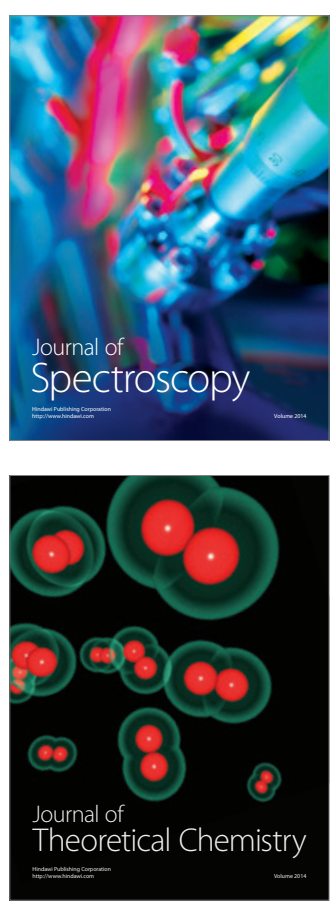
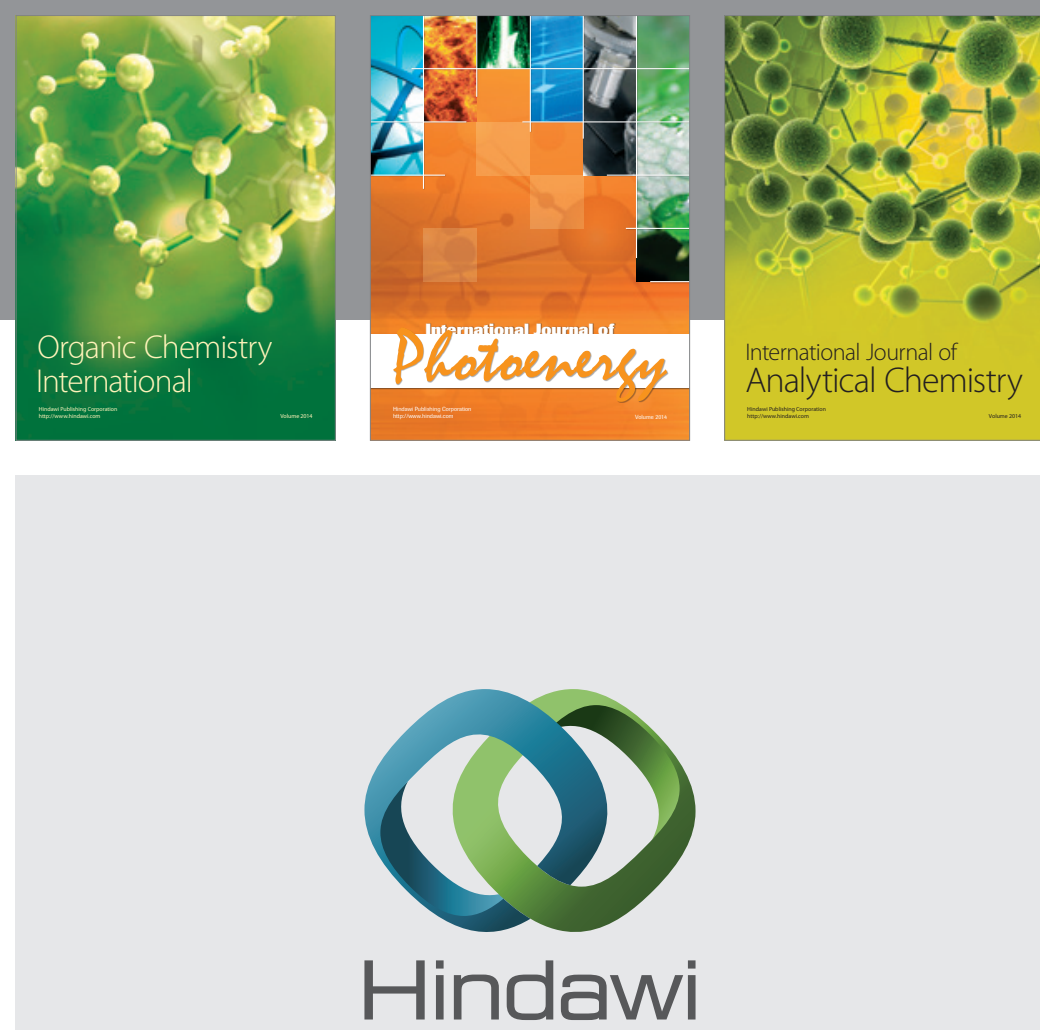

Submit your manuscripts at

http://www.hindawi.com
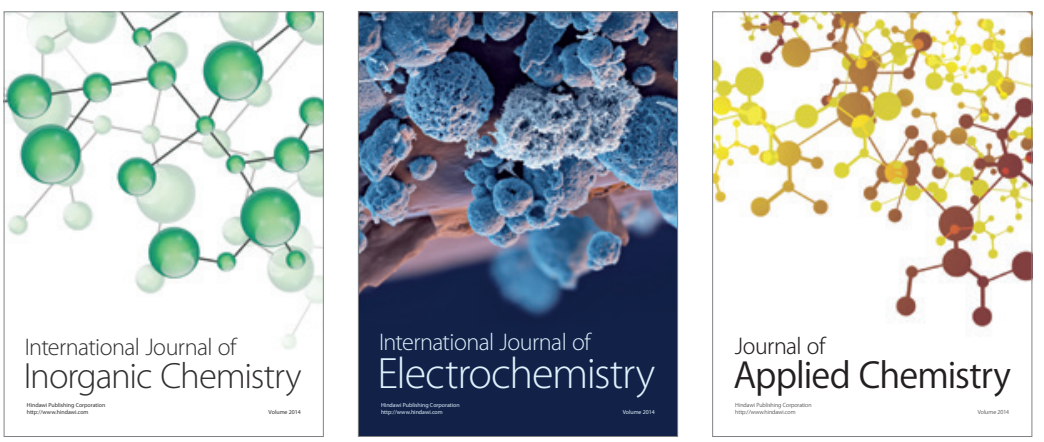

Journal of

Applied Chemistry
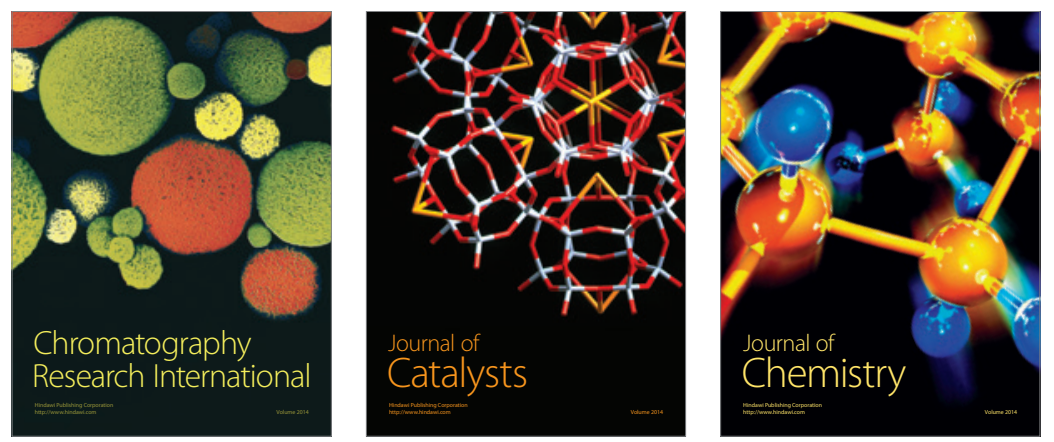
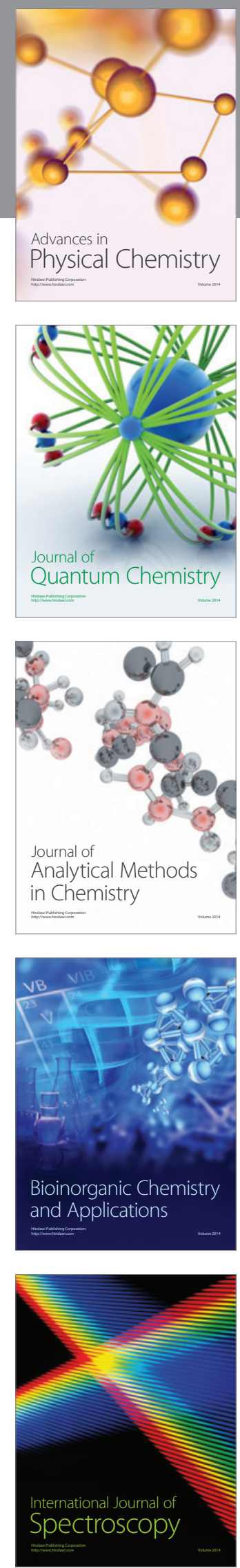